\title{
VÖLKERRECHT AUS BRASILIANISCHER SICHT (ODER MIT BRASILIANISCHEM AKZENT) - ZWISCHEN UNIVERSALISMUS UND REGIONALISMUS
}

Paulo Borba Casella

Professor für Völkerrecht und Vizedekan der Juristischen Fakultät der Bundesuniversität von São Paulo.

Zusammenfassung: Der Artikel ist ein kurzer Bericht einer Vorlesung, die am 04. Juni 2012 an der Humboldt-Universität zu Berlin gehalten wurde.

Schlagwörter: Völkerrecht - Brasilien - Universalismus Regionalismus.

Abstract: The article is a brief report of a conference held on 04 June 2012 at the Humboldt-Universität zu Berlin.

Keywords: Public International Law - Brazil - Universalism Regionalism.

die Macht der Tradition nämlich die alte und feste Zucht, der sicher gewordene Takt von solcher Stärke, dass es das Absterben der alten Geschlechter überdauert und unaufhörlich neue Menschen und Daseinsströme aus der Tiefe in seiner Bann zieht.

O. SPENGLER (1923)²

Quoique l'on en pense la carrière professorale n'est pas de celles qui assurent une parfaite sérénité d'âme. Parce que le cadre dans lequel elle se déroule demeure inchangé, parce que les programmes varient peu, parce que le cours magistral s'insère dans une immuable cérémonie, on croit que cet appareil des rites et des

1 Übersetzung und Überarbeitung: Danielle Campos und Sandra Mahler.

2 SPENGLER, Oswald. Der Untergang des Abendlandes: Umrisse eine Morphologie der Weltgeschichte. Düsseldorf : Albatroz, 2007. Seite 976. 
traditions constitue une carapace qui rend le professeur imperméable aux curiosités et aux inquiétudes de son temps.

G. BURDEAU $(1970)^{3}$

\section{DER „FALL BRASILIEN" - DAS LAND, DAS AUS DEM VÖLKERRECHT ENTSTANDEN IST}

Zwischen der Entdeckung Amerikas im Jahr 1492 durch Cristóvão COLOMBO und der Entdeckung Brasiliens im Jahr 1500 durch Pedro Álvares CABRAL, ist die päpstliche Bulla erlassen und der bilaterale Vertrag von Tordesillas abgeschlossen worden. Dies kennzeichnet den Übergang des Völkerrechtes des mittelalterlichen Systems zum Völkerrecht des modernen zwischenstaatlichen Systems. Beide Ereignisse wurden von Papst ALEXANDER VI. [BORGIA] anerkannt und als legitim bezeichnet, was auf ein klares neues Denken im 16. Jahrhundert hindeutet. Ein Jahr nach dem Erlassen der päpstlichen Bulla haben die Kronen von Portugal und Spanien einen bilateralen Vertrag unterzeichnet, wodurch die Aufteilung Südamerikas und Asiens in Einflusszonen und Kolonien etabliert wurde.

Zwischen 1580 und 1640 wurden Portugal und Spanien von einer gemeinsamen spanischen Krone regiert, was die Verbreitung der Portugiesisch sprechenden Bevölkerung im Hinterland Südamerikas ermöglichte.

1750 wurde der Vertrag von Madrid unterzeichnet und das uti possidetis als Kriterium für die Regelung der Grenzen zwischen dem spanischen und dem portugiesischen Herrschaftsbereich in Amerika instituiert. Von großer Bedeutung war in diesem Zusammenhang der Beitrag von Alexandre de GUSMÃO, ein brasilianischer Diplomat, der Portugal bei den Verhandlungen um den Vertrag von Madrid half und als die verantwortliche Person dafür angesehen wird, dass das brasilianische Herrschaftsgebiet heute mehr als doppelt so groß ist wie im 15. Jahrhundert.

Zwischen 1851 und 1909 konnten die Auseinandersetzungen um die Grenzen zwischen dem Kaiserreich Brasilien (1822-1889) ${ }^{4}$ — und

3 BURDEAU, G. Sur un enseignement impossible. In: Mélanges offerts à Mr. le Doyen TROTABAS. Paris: L.G.D.J., 1970, Seiten 41-50. Seite 41: “le drame, ce n'est pas seulement celui dont la jeunesse a toujours aimé colorer ses défis ou ses rebellions. C'est ainsi celui des hommes qu'on appelle, d'un terme dont aujourd'hui l'ambigüité est évidente, ses maîtres. [...] Il est facile alors de s'insurger contre cette fossilisation et de dénoncer, en termes tantôt voilés et tantôt agressifs, l'incompréhension des maîtres.“

4 Im Jahr 1889 wurde die erste brasilianische Republik gegründet. 
seinen Nachbarstaaten friedlich geregelt werden. In diesem Zeitraum fanden sämtliche unklare Grenzstreitigkeiten, die sich vom Süden - (mit Argentinien) bis in den Norden (mit Guyana, früher Britisch-Guayana und Französisch-Guayana) erstreckten, eine dauerhafte Lösung.

In Hochseegebieten wurden die Unsicherheiten über die Grenzen erst 1982 durch das Seerechtsübereinkommen der Vereinten Nationen beendet, welches das 200 Seemeilen große Küstengewässer konsolidierte. Allerdings wurde dieses Übereinkommen Anfang der siebziger Jahre von einem brasilianischen Gesetz antizipiert. Dieses Gesetz hat sogar eine größere Schelfplattform - den sogenannten „Blauen Amazonas“ - anerkannt. Dieses erweiterte Küstengewässer entspricht heute einer zusätzlichen Hälfte des brasilianischen Herrschaftsgebietes, in dem sich die Exploration der Erdöllagerstätten, die tief unter einer dicken Salzschicht unter dem Meeresboden liegen, als bedeutender Wirtschaftsfaktor für das Land in naher Zukunft darstellt.

Brasilien wurde erstmal ein Staat und später dann eine richtige Nation. Dies wird deutlich, wenn man z. B. die frühere Stellung des Landes bei den Außenbeziehungen betrachtet. Erst im Jahr 1822 hat sich das brasilianische Reich von Portugal unabhängig erklärt, allerdings hat das Land schon seit 1815, als es noch Vereinigtes Königreich von Portugal, Brasilien und den Algarven (Reino Unido de Portugal, Brasil e Algarve) war, am Wiener Kongress teilgenommen.

Die durch ein nationales Gesetz vom 11. August 1827 vorgesehene Gründung der Rechtshochschulen von São Paulo und Olinda stellte eine wichtige Wende dar ${ }^{5}$. Bereits ein Jahr nach dem Inkrafttreten des Gründungsgesetzes wurden beide Hochschulen eröffnet. In Brasilien wurde das Rechtsstudium Anfang März 1828 am Lehrstuhl für Kirchenrecht, Diplomatisches Recht und Völkerrecht (Direito Eclesiástico, Diplomático e das Gentes) der Hochschule von São Paulo eingeführt. Professor José Maria AVELLAR BROTERO - ein gebürtiger Portugiese, der iuris doctor von Coimbra war und erst 1833 in Brasilien eingebürgert wurde - war der erste ordentliche Rechtsprofessor des Landes und für diese wichtige Vorlesung zuständig. Er hat im Jahr 1829 das Lehrbuch „Princípios de Direito Natural“ (Prinzipien des Naturrechtes) veröffentlicht, welches heutzutage als das erste im Lande verfasste Werk im Bereich des Völkerrechts gilt ${ }^{6}$, drei Jahre vor der Veröffentlichung des Lehrbuchs „Elementos de Derecho de Gentes“ (Grundzüge des Völkerrechts) von Andrés BELLO im Jahr 1832. Das Werk von Brotero ist nach einer Kontroverse, die Rückwirkungen im Parlament hatte, aus den Lehrstühlen der Juristischen Fakultät entfernt

5 Die Rechtshochschule von São Paulo wurde im März 1828 gegründet, die von Olinda (später nach Recife verlegt) im Mai 1828.

6 BROTERO, José Maria Avellar. Principios de direito natural. Rio de Janeiro: Typographia Imperial Nacional, 1829. 
worden. Brotero hat aber später, nämlich im Jahr 1836, noch ein Werk veröffentlicht, die ,Questões sobre presas marítimas ${ }^{667}$.

Am Anfang von „Questões sobre presas marítimas“ widmet AVELLAR BROTERO den Lesern sein Werk ("aos leitores") und behauptet, dass seine Methode objektiv sei und von subjektiven Betrachtungsweisen absieht ${ }^{8}$. In den folgenden Kapiteln analysiert der

7 BROTERO, José Maria de Avellar. Questões sobre presas marítimas: oferecidas ao cidadão Rafael Tobias de AGUIAR pelo autor J. M. A. BROTERO. São Paulo: Typographia de Costa Silveira, 1836: “Com a proteção de V. Exa. me animo a fazer publicar uma pequena obra com o título - Questões sobre presas marítimas - fruto de algum trabalho, e que julgo servirá para dar algumas idéias àqueles que tem de julgar e defender objetos tão interessantes. / A benevolência de V.E. relevará a falta de estilo, e os erros da doutrina; doutrina assaz espinhosa e bem pouco conhecida entre nós. Não tendo eu ao meu alcance senão os meus próprios livros, heide por força cair em omissões." In der zweiten Ausgabe (1863) BROTERO, José Maria de Avellar. Questões sobre presas marítimas: segunda edição augmentada. São Paulo: Typographia imparcial - de J. R. de Azevedo Marques, 1863., hielt im Vorwort fest: "Conheço que este meu trabalho é imperfeito, e muito sinto que nesta segunda edição ficasse com tantos erros, resta-me a esperança que os homens competentes hão de ter indulgência com tais defeitos, e só censurar a doutrina e nesta parte peço-lhes severidade, pois pedir considerações seria ter em pouco a ciência e o meu dever. / Este livro não é uma obra de teorias ou doutrinas especulativas; é um compêndio de fatos e princípios do Direito Marítimo admitido pelas nações civilizadas. / Da primeira edição suprimi tudo quanto me pareceu fora da matéria, aumentei porém muita doutrina que faltava. / Cito os escritores, de que tenho notícia, que publicaram suas obras depois da minha primeira edição - 1836. / Nesta segunda edição procurei ser útil aos meus Escolares, no estudo do Direito das Gentes, e não olhei, nem me lembrei, que o meu trabalho pudesse ser estimado pela elegância e pureza de linguagem".

8 BROTERO, José Maria de Avellar. Questões sobre presas maritimas: oferecidas ao cidadão Rafael Tobias de AGUIAR pelo autor J. M. A. BROTERO. São Paulo: Typographia de Costa Silveira, 1836: "eu vou tratar de - direito positivo - e por isso o meu desejo e obrigação é mostrar-vos quais os tratados, manifestos e mais peças diplomáticas, que existem sobre o presente objeto; quais as leis, regulamentos e determinações das Nações sobre o seu direito - marítimo particular : quais as decisões dos tribunais das Nações influentes, e quais seus usos e costumes que formam o Direito das gentes tácito ou voluntário. Eu procuro seguir o método ensinado por KLÜBER - dogmático-histórico - esclarecendo as matérias com fatos, com acontecimentos reais. Recorro ao Direito das gentes absoluto, quando o caso é duvidoso, ou quando sobre ele não concordam as convenções e os usos. Desprezo as opiniões dos antigos escritores (aqueles que tive ao meu alcance), que só se fundam no Direito romano ou seguem opiniões particulares, filhas ou da localidade, ou do partido". Und weiter: "Muitas vezes, na confusão dos pareceres dos JJ. entre si contraditórios eu me animo a dar a minha opinião. A legislação pátria é citada nos lugares competentes. Muito desejava alegar os julgamentos dos nossos tribunais, mas não estava ao meu alcance poder satisfazer o meu desejo. / Eu conheço que o meu trabalho está bem longe da perfeição e conheço que ele está muito longe de poder conseguir o seu fim : conheço e confesso que não tive à mão nem a legislação das Nações do norte da Europa, nem muitos bons autores que têm tratado desta matéria, e que eu devia consultar; mas minha consciência está convencida de que esta minha pequena obra sempre há de prestar alguma utilidade aos meus escolares, e ao público. Julgo que a matéria é muito interessante, e que por esta razão o governo, e os sábios, não me deixarão continuar a transmitir 
Autor wichtige Aspekte des Seerechts und nach einer objektiven Ansicht des internationalen Rechtes bezeichnet er z. B. die Beschlagnahme von Schiffen vor einer offiziellen Kriegserklärung als ungerecht ${ }^{9}$. Zu diesem spezifischen Thema scheint sich der jetzige Stand der Außenpolitik kaum geändert zu haben ${ }^{10}$.

Die lokale Geschichte der Hochschule auf dem Largo de São Francisco weist klare Ähnlichkeiten mit der nationalen Geschichte Brasiliensauf.NeunBundespräsidentenhabenanderJuristischenFakultät studiert. Darüber hinaus haben mehr als vierzig Ministerpräsidenten des Bundeslandes São Paulo (das allein 40 Mio. Einwohner hat und für den Großteil des brasilianischen Bruttoinlandsproduktes verantwortlich ist), sowie über sechzig Richter des Brasilianischen Obersten Bundesgerichts (Supremo Tribunal Federal) und einige Staatsminister des Militärregimes (1964-1985) ihren Abschluss an der Universität von São Paulo gemacht. Die Fakultät sollte nicht nur als

na aula minhas opiniões à mocidade, uma vez que elas sejam falsas. O governo me advertirá e os sábios me esclarecerão, com suas luzes, por meio da imprensa".

9 BROTERO, José Maria de Avellar. Questões sobre presas marítimas: segunda edição augmentada. São Paulo: Typographia - imparcial - de J. R. de Azevedo Marques, 1863. Seiten 7-8: "se é legal a presa feita antes da declaração, decreto e manifesto de guerra ?" Auf die Frage antwortet BROTERO: "É uma das questões bem controvertidas pelos jurisconsultos que tratam deste assunto : - entre si disputam eles a primazia; e todos se fundam em fatos praticados pelas Nações, e dos quais querem deduzir a sua regra de Direito marítimo. Nós seguimos a opinião daqueles que adotam a afirmativa, não só porque nos parece mais conforme aos princípios de Direito das gentes absoluto, como também por estarmos convencidos, que a prática constante das Nações tem admitido como um princípio certo, que a presa feita antes da declaração de guerra é ilegal". Und Seiten 8 f.: "Não negamos os fatos em que se fundam os nossos adversários, antes reconhecemos que na história marítima de quase todas as Nações acham-se guerras principiadas por meio de presas antes de declaração, e em BYNKERSHOEK vem em resumo algumas delas citadas". Brotero zitiert "BYNKERSHOEK, Tratado das leis de guerra (edição de Filadélfia), Seite 15 f." und in derselben Ausgabe aus dem Jahr 1863: "Veja-se F. de CUSSY, Phases et Causes célèbres du Droit maritime des Nations, L. 1, tit. 3, par. 4, L. 2, cap. 11 ".

10 BROTERO, José Maria de Avellar. Questões sobre presas maritimas: segunda edição augmentada. São Paulo: Typographia - imparcial - de J. R. de Azevedo Marques, 1863. Seite 9: "As Nações reconhecem o odioso de tal procedimento, e sempre procuram defender-se com falsas razões, fazendo recair em seus adversários a causa das hostilidades”. Ein verschiedener Text in der Ausgabe aus dem Jahr 1836, Seite $5 \mathrm{f}$.: "mas em regra de direito, abusos não formam lei, e tais exemplos das Nações também não a podem formar, visto que elas mesmas reconhecem o odioso e ilegal de tal procedimento, defendendo-se com pretextos de uma falsa necessidade, ou procurando provar que sua adversária já tinha iniciado as hostilidades, e que portanto não era necessária a declaração; asserção reconhecida entre todas as Nações, princípio este verdadeiro e que nós confessamos: mas na história só o achamos aplicado a pretextos, que servem para escurecer a verdade, e muitas vezes sem o menor fundamento. (...) Contudo, a mesma Inglaterra não se atreve a negar o princípio da necessidade da declaração de guerra, para a legalidade da presa, e só sim estabelece como princípio seu - o direito de reciprocidade." 
eine Rechthochschule (escola de direito), sondern auch als eine Schule für Staatsregierung (escola de governo) anerkannt werden.

Zurück kommend zu dem Panorama der brasilianischen Völkerrechtstheorie im 19. Jahrhundert, bezeichnete Antonio Pereira PINTO $1864^{11}$ die friedliche Lösung von Streitfällen zwischen Ländern mit erheblichen Machtunterschieden als Zweck des Völkerrechts ${ }^{12}$. In seiner vierbändigen „Sammlung der brasilianischen Praxis im Völkerrecht" von 1864 stellte Pinto schon fest, dass selbst wenn Brasilien, im Vergleich zu europäischen Mächten, trotz internationaler Verträge, (oder sogar wegen der internationalen Verträge) nicht sehr erfolgreich sei, wäre es immer noch wesentlich im internationalen

11 PINTO, A Pereira. Apontamentos para o direito internacional. Brasília: Ministério da Justiça/UnB, 1980. Seiten 1-2: "é lícito todavia ponderar que, achando-se esparsos os tratados que temos celebrado com diferentes potências estrangeiras e outros inéditos, a reunião deles em um só corpo, acompanhada de sucintas apreciações históricas, como o fizemos, da transcrição de documentos hoje raros, e da legislação peculiar às convenções mais importantes, deve, sem controvérsia, aproveitar àqueles que intentarem escrever o direito internacional brasileiro. $\mathrm{E}$ assaz compensados seremos dos labores desta tarefa, se para a edificação daquele grandioso edifício servir de pequeno seixo o nosso insignificante trabalho."

12 PINTO, A Pereira. Apontamentos para o direito internacional. Brasília: Ministério da Justiça/ UnB, 1980. Seiten 3-4: "a jurisprudência que se encaminha a estabelecer a confraternidade entre os povos do universo, ligando-os pelos nós do comércio, das indústrias e da propagação de todos os conhecimentos úteis, que tem por alvo realizar a solução das desavenças entre as nações pelos meios da discussão ilustrada e calma, é uma das mais belas conquistas da inteligência humana". Und weiter: "E, se infelizmente essa jurisprudência não tem atingido toda a perfeição de que é suscetível, se o orgulho das grandes potências impele-as ainda a lançar mão dos remédios violentos para extorquirem dos povos fracos concessões humilhantes e vantajosas somente à sua avidez, se contra nosso próprio país têm sido cometidas enormes vexações por um dos estados mais poderosos da Europa, apezar dos tratados, ou por causa dos tratados, se em geral o Império não tem auferido grandes lucros com a celebração dos contratos internacionais, tais fatos nem abalam a doutrina que deixamos expendida, nem por motivo deles devemos confiar menos em que uma reação se há de ir operando, entre as nações cultas, ou para referearem os ímpetos belicosos de seus governos, apontando-lhes a trilha da discussão diplomática como oportuno e exclusivo recurso, para terminar as dissidências que acaso apareçam com estranhos países, ou para aconselhar-lhes que nos tratados com os estados de ordem menos importante guardem sempre a devida reciprocidade, não lhes impondo pactos leoninos que trazem ordinariamente em si o gérmen de futuras contestações.”. Und noch: "Radicado, pois, esse pendor que se vai manifestando entre os países cultos para desenlaçarem pacificamente, pelos meios diplomáticos, e não pela espada do mais forte, as dissenções que surgem entre os povos e apertadas as suas relações de mútuo comércio e alianças pelo desenvolvimento do vapor e da eletricidade, não longínquos horizontes se devassam ao olho do observador perspicaz, nos quais se enxerga a lisonjeira época de uma tão perfeita e recíproca uniformidade de interesses internacionais, que não poderá ser violada, ainda pelos estados poderosos, sem total detrimento de sua prosperidade e grandeza. / E, pois, a aproximação dessa lisonjeira situação deve ser fervorosamente almejada por todos os homens generosos, por todos os estadistas e filantropos." 
System tätig zu sein.

Die Dichotomie zwischen Universalismus und Regionalismus hat sich an der brasilianischen Außenpolitik in mehreren Fällen herausgestellt. Beispiel davon ist die Absage der Einladung zum Kongress von Lima (1877-78) zur Kodifikation des Internationalen Privatrechts. Die höfliche Ablehnung wurde von der folgenden Fragestellung begleitet: warum sollte Brasilien auf der regionalen Ebene das thematisieren, was gerade weltweit schon verhandelt worden war - z.B. in Europa. Die erwähnte Frage ist heutzutage gewissermaßen immer noch zu erkennen an der intensiven Tätigkeit des Landes in regionalen Initiativen - z.B. im MERCOSUR - aber auch als „Global Player" - z.B. auf der Ebene der BRICS-Staaten.

Die Initiativen bei den Panamerikanischen Kongressen - ab Ende des 19. Jahrhunderts - und die entsprechenden Kodifikationen des Internationalen Privatrechts und des Völkerrechts sind neben den späteren Interamerikanischen Verträgen ( $\mathrm{ab}$ 1948) weitere Beispiele der brasilianischen Performance auf der regionalen Ebene. Die Mitgliedschaft in der OAS - Organisation Amerikanischer Staaten und die völkerrechtlich relevante Anerkennung der Gerichtsbarkeit des interamerikanischen Gerichtshofs für Menschenrechte ${ }^{13}$ sind sehr konsolidiert. Zwei neue Fälle - Guerrilha do Araguaia und Belo Monte - deuten auf eine Änderung der Lage hin ${ }^{14}$.

Der Aufbau eines weltweit geltenden postmodernen Völkerrechtssystems erfolgt schon seit Jahrzehnten - so meine These in „Grundzüge des postmodernen Völkerrechts “ $(2008)^{15}$ - wobei hier eine genaue Unterscheidung zwischen Völkerrecht und internationalen Beziehungen klar betont werden soll ${ }^{16}$.

13 Der Gerichtshof wurde 1969 auf Grundlage der Amerikanischen Menschenrechtskonvention (AMRK), gegründet, diese trat aber erst Anfang der 90er Jahren in Brasilien in Kraft.

14 KOSKENNIEMI, Martti. The gentle civilizer of Nations: the rise and fall of international law 1870-1960. Cambridge: University Press, 2001. notiert den Zustand der Entwicklung und wie waren damaligen Eigenschaften des Vökerrechts, und vergleicht die Lage, Deutschland, Frankreich, England und wie es sich auberhalb Europa zeigte, folgend Carl SCHMITT, Hans MORGENTHAU und die Bedeutung der Änderungen des Völkerrechts für die Außenbeziehungen in den Vereinigten Staaten.

15 So CASELLA, Paulo Borba. Fundamentos do direito internacional pós-moderno. São Paulo: Quartier Latin, 2008: 'direito e relações internacionais: coexistência pacífica?', Seiten 889-972.

16 MAROTTA RANGEL, V.. Introdução aos princípios do direito internacional contemporâneo de A. A. CANÇADO TRINDADE. In: TRINDADE, Antonio Augusto Cançado. Princípios do direito internacional contemporâneo. Brasília: Ed. UnB, 1981, Seiten v-xiv, cit. p. vii, verteilt in vier historischen Schritte die Rechtslehre in Brasilien: "que refletem, preponderantemente, eventos básicos de períodos históricos sucessivos" (...) "Em verdade, a simples menção das balisas que marcam o início e o fim de cada etapa, nos sugere a profundidade das transformações por que tem passado as condições sociais e políticas da sociedade contemporânea, em que o 
direito internacional - como todo direito - se assenta (...) das obras publicadas no Brasil, nessa quarta e última etapa, algumas poderiam a ela naturalmente pertencer por simples circunstância de ordem cronológica. Tal não ocorre com o livro que me cabe a honra de proemiar, porquanto ele significa uma resposta sensível e vital a indagações essenciais que marcam a presença do direito das gentes em nossos dias. Situa-se ele, por sinal, no centro de convergência de três termos inseridos no título com que se denomina e se apresenta ao público: Princípios do direito internacional contemporâneo. O primeiro desses termos distingue a obra por mencionar princípios, aos quais ela deseja cingir-se, já que o seu escopo não consiste em expor a sistemática diversificada, abrangente e complexa do direito das gentes mas as diretrizes de temas nucleares e vitais, desdobrados em partes, quatro ao todo: fontes, responsabilidade dos estados, competências das organizações internacionais, e, finalmente, posição internacional dos particulares. O segundo desses termos concerne ao próprio direito internacional cujas origens remontam, pelo menos em sua feição moderna, à época da descoberta do novo mundo, mas cujas estruturas e lineamentos sofrem o influxo das transformações sociais, a influência do progresso tecnológico e científico, o vigoroso condicionamento dos fatores políticos, econômicos, culturais. Trata-se, pois, a rigor do international law, segundo a terminologia dos países de common law, do qual se exclui necessariamente o direito internacional privado, conflict of laws. Precisamente em razão do impacto dessas transformações, o terceiro dos termos inseridos no título consiste no qualificativo de contemporâneo, outorgado a esse direito internacional, que se deseja entrever, difundir e analisar à luz dos eventos da década de oitenta, considerado na perspectiva dos momentos decisivos da sociedade global de que todos participamos como membros, mais expectadores que protagonistas.”. Der Autor behauptet noch, dass zwischen der Unabhängigkeit Brasiliens und der Konferenz des Haages im Jahr 1907 "o ensino do direito das gentes (segundo então era denominado) se iniciou com a instalação dos cursos jurídicos entre nós (...) Os professores que primeiro lecionaram matérias próprias a esse direito na Academia de São Paulo foram AVELAR BROTERO e AMARAL GURGEL que alternadamente o regiam. Coube àquele escrever a primeira obra de direito internacional público no Brasil: Questões sobre presas marítimas, editada em 1836, em São Paulo, que surgiu, como se verifica, apenas quatro anos depois da edição dos Princípios de derecho das gentes, da autoria de Andrés BELLO, obra marcante na bibliografia latino-americana”. Er zitiert noch Lafayette Rodrigues PEREIRA und den Barão do RIO BRANCO, Seite v f.: "Prioridade do ensino em Olinda coube a Lourenço José RIBEIRO e Pedro Autran da MATTA E ALBUQUERQUE. Deste último, que prelecionou em Pernambuco, por mais de cinco décadas, é a autoria dos Elementos do direito das gentes segundo a doutrina dos escritores modernos, editado em 1851. Com o escopo de completá-lo e atualizá-lo subseqüentemente, dois outros cursos se publicaram no Recife, também da lavra de docentes da mesma escola: as Preleções de direito internacional, de Antonio de Vasconcellos Menezes de DRUMMOND, e as Lições elementares do direito das gentes, de João Silveira de SOUZA, datadas de 1867 e 1889, respectivamente. Foram também editados na segunda metade do século passado os Elementos de direito internacional marítimo, de Carlos Vidal de Oliveira FREITAS, e os Apontamentos para o direito internacional, ou coleção completa dos tratados celebrados pelo Brasil, de Antonio Pereira PINTO, repositório, em quatro volumes, de documentos de relevância, nas relações exteriores de nosso país. Todas as publicações do século passado estão como que a preparar o advento da obra marcante do primeiro período, os Princípios de direito internacional, de Lafayette Rodrigues PEREIRA, obra em dois tomos, publicada em 1902. Jurista de escol, no plano da teoria e da prática, avulta como se sabe, na última etapa do primeiro período, a prolongar-se no segundo, o Barão do RIO BRANCO.” V. MAROTTA RANGEL (cit., 1980, Seite vi): “teve ampla repercussão entre nós e estimulou estudos em profundidade do direito internacional (...) a começar pelos realizados 


\section{LITERATURVERZEICHNIS.}

BROTERO, José Maria Avellar. Princípios de direito natural. Rio de Janeiro: Typographia Imperial Nacional, 1829.

BROTERO, José Maria de Avellar. Questões sobre presas marítimas: oferecidas ao cidadão Rafael Tobias de AGUIAR pelo autor J. M. A. BROTERO. São Paulo: Typographia de Costa Silveira, 1836.

BROTERO, José Maria de Avellar. Questões sobre presas marítimas: segunda edição augmentada. São Paulo: Typographia - imparcial - de J. R. de Azevedo Marques, 1863.

BURDEAU, G. Sur un enseignement impossible. In: Mélanges offerts à Mr. le Doyen TROTABAS. Paris: L.G.D.J., 1970, pp. 41-50.

BYNKERSHOEK. Tratado das leis de guerra. Filadélfia, 1863.

CASELLA, Paulo Borba. Fundamentos do direito internacional pósmoderno. São Paulo: Quartier Latin, 2008.

CUSSY, F. de. Phases et Causes célèbres du Droit maritime des Nations. Leipzig: Brockhaus, 1856.

pelo próprio chefe da delegação brasileira à Conferência, Ruy BARBOSA, e continuados com os Elementos de direito internacional, de autoria de Manuel Augusto de Sá VIANA e a Evolução do direito internacional, de João CABRAL, que vieram à lume em 1908, no Rio de Janeiro. Em 1911 Epitácio PESSOA divulgou o seu Projeto de código de direito internacional público, no Rio de Janeiro. Do mesmo ano e da mesma cidade é o Direito internacional público (com segunda edição em 1939) de Clóvis BEVILAQUA.”. V. MAROTTA RANGEL (cit., 1980, Seite vi): "durante a terceira etapa se editaram exposições sistemáticas (...) como as de Raul PEDERNEIRAS, Direito internacional compendiado (1931) e de Braz de Souza ARRUDA, Estrutura do direito internacional (1938), sobressaindo-se o Tratado de direito internacional público, em três tomos, de Hildebrando ACCIOLY, editado entre 1933 e 1935 (com segunda edição em 1956). Em 1936 publicaram-se no Rio de Janeiro, Gênese e evolução da neutralidade e Natureza jurídica do mar, de autoria, respectivamente de Linneu de Albuquerque MELLO e Breno Machado Vieira CAVALCANTI. Embora dedicado ao direito internacional privado, Haroldo VALLADÃO analisou temas de internacional público, a que deu desenvolvimento na etapa ulterior.". MAROTTA RANGEL, V.. Public international law: the last five decades. In: DOLINGER, Jacob DOLINGER; ROSENN, Keith. A panorama of Brazilian Law. Miami/ Rio: Univ. of Miami North-South Center/Ed. Esplanada, 1992, Seiten 287-308, cit. Seite 290, während des Krieges "The profound abnormality of war period adversely affected the production of scholarly studies" und dazu MAROTTA RANGEL, V.. Introdução aos princípios do direito internacional contemporâneo de A. A. CANÇADO TRINDADE. In: TRINDADE, Antonio Augusto Cançado. Princípios do direito internacional contemporâneo. Brasília: Ed. UnB, 1981, Seite vii: “desde o último conflito armado mundial, o direito das gentes, sem perder o sentido natural de continuidade no tempo e de sorte a refletir o rumo e o espírito das mudanças por que tem passado a comunidade internacional, ampliou extraordinariamente o seu âmbito de competência ratione materiae (...) O desenvolvimento dos estudos do direito internacional público, em nosso país, tem estado a acompanhar-lhe as vicissitudes de transformação e relevância crescente, como atestam os trabalhos de docência, de pesquisa e de orientação conduzidos por eminentes juristas, que hoje o cultivam, com segurança e descortino, nas diversas cátedras e departamentos das universidades brasileiras, assim como na diplomacia." 
KOSKENNIEMI, Martti. The gentle civilizer of Nations: the rise and fall of international law 1870-1960. Cambridge: University Press, 2001. MAROTTA RANGEL, V.. Introdução aos princípios do direito internacional contemporâneo de A. A. CANÇADO TRINDADE. In: TRINDADE, Antonio Augusto Cançado. Princípios do direito internacional contemporâneo. Brasília: Ed. UnB, 1981.

MAROTTA RANGEL, V.. Public international law: the last five decades. In: DOLINGER, Jacob DOLINGER; ROSENN, Keith. A panorama of Brazilian Law. Miami/Rio: Univ. of Miami North-South Center/Ed. Esplanada, 1992.

PINTO, A Pereira. Apontamentos para o direito internacional. Brasília: Ministério da Justiça/UnB, 1980.

SPENGLER, Oswald. Der Untergang des Abendlandes: Umrisse eine Morphologie der Weltgeschichte. Düsseldorf : Albatroz, 2007. 